\title{
O discurso de germanidade reproduzido pelo poder público em Marechal Cândido Rondon
}

\section{The germanness discourse reproduced by the public power in Marechal Cândido Rondon}

\section{Franciele Maria Martiny*}

RESUMO: Neste estudo, objetiva-se verificar como o Poder Público municipal de Marechal Cândido Rondon, Paraná, (re)constrói o discurso de germanidade do município, por meio da análise de enunciados e imagens da arquitetura local presente em banners que são colocados nos eventos oficiais promovidos na localidade. $O$ interesse pelo assunto deve-se à necessidade da contextualização histórico-social para a pesquisa realizada sobre o ensino da Língua Alemã no município, por meio das políticas linguísticas e educacionais em torno da referida língua de imigração. Para a compreensão das condições de produção do discurso de germanidade e da reprodução, será utilizado o aporte teórico possibilitado pela Análise do Discurso (AD), de linha francesa, que leva em consideração as relações intrínsecas entre a língua, o sujeito, a história e o poder ideológico presentes na enunciação, ou seja, uma visão macro do fenômeno linguístico. Como resultado, verifica-se como o Poder Público utiliza-se de elementos simbólicos, imagéticos, que reproduzem efeitos de sentidos a fim de manter uma identidade re(criada) do município, silenciando as demais etnias também presentes no local.

PALAVRAS-CHAVE: Análise do discurso. Germanidade. Poder público. Marechal Cândido Rondon.

ABSTRACT: This study aims at verifying how the municipal public power (re)builds the Germanness discourse of the Marechal Cândido Rondon city, through the analysis of statements and images of the local architecture, present in banners, which are spread in official events promoted in the city. The interest on the subject comes from the need of a historical-social contextualization for the research carried out about the German language teaching in the city, by means of linguistic and educational policies about the mentioned immigration language. However, at this moment, to comprehend the production conditions of the Germanness discourse and its reproduction, it will be used the theoretical support from the French Discourse Analysis, which considers the intrinsic relationships among language, subject, history and ideological power found in the enunciation, in other words, a macro view of the linguistic phenomenon. As a result, it has been verified how the public power uses symbolic and imagery elements that reproduce sense effects to keep a (re)built identity of the city, silencing the other ethnicities also present in the locality.

\footnotetext{
* Professora adjunta da Universidade Federal da Integração Latino-Americana (UNILA), Doutora em Letras pela Universidade Estadual do Oeste do Paraná (UNIOESTE). E-mail: franciele.martiny@unila.edu.br.
}

Entretextos, Londrina, v. 15, n. 2, p. 95-108, jul./dez. 2015. 
KEYWORDS: Discourse analysis. Germanness. Public power. Marechal Cândido Rondon.

\section{Considerações iniciais}

O município de Marechal Cândido Rondon está localizado no extremo Oeste do Paraná, sendo reconhecido, na região, como centro turístico essencialmente germânico, por meio de símbolos e estereótipos que remetem a esse discurso do já-dito.

Isso é sustentado discursivamente, materializando-se em diferentes enunciados, bem como no próprio estilo arquitetônico de parte de edificações presentes na localidade, as quais possuem fachadas representativas da arquitetura alemã que foram incentivadas pelo poder público municipal para dar essa característica germânica à cidade.

Trata-se de uma memória discursiva (re)produzida frequentemente pelos veículos de comunicação, por pioneiros e descendentes, ou mesmo por leis e no incentivo a eventos festivos (Oktoberfest e festas de aniversário do município), perpetuando a mesma imagem do povo de origem germânica presente na cidade, desde a sua colonização.

Nesse sentido, a imagem do germanismo rondonense está amplamente apoiada na produção de efeitos de sentido que grande parte da própria população evidencia em seus enunciados, orais e escritos, baseados no discurso reproduzido dos governantes e dos (i)migrantes de descendência alemã.

Um exemplo dessa situação é a iniciativa do Governo Municipal na produção três grandes banners $(3 \mathrm{~m} \times 2 \mathrm{~m}$ ) que são levados aos eventos oficiais e colocados com destaque nos locais. Neles há imagens de construções de prédios públicos e pontos turísticos do município que possuem a arquitetura em estilo germânico na sua composição, contendo, além disso, o seguinte enunciado acima das imagens: "Nossa história e nossa gente têm raízes na origem alemã". 
É a partir desse corpus que se pretende, com base nos pressupostos da Análise do Discurso (AD) francesa, considerar a historicidade da linguagem presente na colonização do município rondonense, iniciada na década de 1950, pela Colonizadora Industrial Madeireira Colonizadora Rio Paraná S/A - Maripá. Até porque, foi a referida empresa que direcionou, propositadamente, as vendas de terras apenas a descendentes de imigrantes alemãs, inviabilizando que outras etnias se estabelecessem na localidade, naquela época.

Considera-se que pelo viés do discurso, a análise vai além dos elementos linguísticos internos da língua, analisando também os fatores extralinguísticos envolvidos na enunciação, evidenciando as complexas relações ideológicas, uma vez que a $A D$ leva

[...] em conta o homem e sua história, considera os processos e as condições de produção da linguagem, pela análise da relação estabelecida pela língua como os sujeitos que a falam e as situações em que se produz o dizer. (ORLANDI, 2005, p. 16).

A partir disso, observa-se a grande contribuição da referida disciplina ao afirmar que não há neutralidade nos discursos, nem mesmo no mais trivial deles, pois sempre existe o simbólico produzindo e reproduzindo sentidos. Ou seja, não há um sentido único, fechado, mas efeitos de sentidos.

Como afirma Orlandi (2005, p. 20), mesmo

[...] as palavras simples do nosso cotidiano já chegam até nós carregadas de sentidos que não sabemos como se constituíram e que, no entanto, significam em nós e para nós. Desta maneira, a cultura e a história de um povo afeta a linguagem e seus sentidos.

A partir desse direcionamento, nota-se uma crítica à visão de neutralidade da linguagem, centrada nos estudos imanentes da língua, pelo viés estruturalista, quando apenas se focalizava a estrutura interna do sistema linguístico. Já para a $A D$, a língua é opaca, não neutra, e está situada na interação social. 
Pêcheux (1969), em estudos sobre o discurso, critica o esquema elementar da comunicação, dizendo que o discurso não é apenas a transmissão de uma informação (mensagem), mas é efeito de sentido entre os interlocutores. Ou seja, é no próprio discurso que se apresenta a relação intrínseca entre língua e ideologia, uma vez que não existe sujeito que não esteja inserido em uma determinada formação discursiva, a qual determina o que o sujeito pode e não pode dizer e em que situações. É sob este viés que a análise será feita na sequência.

Para tanto, o artigo aborda, na próxima seção, aspectos relacionados à construção do discurso da germanidade no município, para após, relacioná-lo ao corpus de análise.

\section{Os percursos do discurso "alemão" rondonense}

Como já mencionado na introdução do texto, o corpus de análise deste estudo é formado por três banners produzidos e utilizados em eventos oficiais do município rondonense. Quando não há eventos, esses são colocados nos corredores da prefeitura, em pontos diversos, com grande destaque visual.

Com base em pesqusia sobre o município rondonense, retomanto aspectos históricos, é possível recuperar o processo colonizatório da região, feito na década de 1950, que direcionou as terras, em sua maior parte, para grupos teuro-brasileiros. Essa memória é resgatada constantemente na situação atual do município, uma vez que o Poder Público realiza ações para continuar a reproduzir uma imagem teuta, a resgatar a cultura alemã, apagando todas as ações coercitivas as quais proibiram outras etnias de comprar terras durante a colonização.

Verifica-se também a relação entre a empresa colonizadora e a igreja como responsáveis, em grande parte, pela propaganda do município aos colonos a fim de incentivá-los a migração. A maioria dos religiosos era filhos de 
descendentes de imigrantes, falantes de dialetos, incentivadores da migração. "O sagrado se constituía em fator influenciador de negócios" (GREGORY; STEIN, 2011, p. 354).

Ainda sobre a hegemonia populacional, Targanski (2007) enfatiza a dificuldade de aceitação de outros povos na localidade, sendo que cada vez mais os grupos homogêneos se estabeleciam, amparados pela empresa responsável pela colonização que criava empecilhos para intimidar a migração de outros que não fossem descendentes europeus.

Segundo o autor supracitado, os obstáculos eram diversos, passando

[...] desde a recusa da colonizadora em vender os lotes de terra sob as mesmas condições para estes outros imigrantes, passando pela intimidação cultural e lingüística, e até mesmo na religião, com a formação de igrejas luteranas e católicas, onde a eucaristia e o cerimonial eram realizados em língua alemã (TARGANSKI, 2007, p. 27-28).

Nota-se, a partir disso, que o processo de colonização de toda a região Oeste, bem como de Marechal Cândido Rondon, foi direcionado. Essa situação também pode ser confirmada, quando Saatkamp (1984) mostra pesquisas de 1956 em que a população rondonense era constituída por 95\% de famílias descendentes de alemães, enquanto os 5\% restantes pertenciam a famílias italianas ou luso-brasileiras. Até vinte anos atrás, em 1990, a situação permaneceu quase igual, totalizando $85 \%$ de descendentes alemães no município.

A mesma estudiosa aponta a Maripá (que foi instalada no município rondonense por um grupo de gaúchos) como sendo a responsável pela busca de mão de obra para as "novas terras" 1, privilegiando agricultores gaúchos e catarinenses (descendentes de italianos e alemães), uma vez que estes eram vistos como os mais aptos ao serviço.

\footnotetext{
${ }^{1}$ Chamadas de Vila General Rondon, na época distrito de Toledo.
} 
Além disso, a hegemonia populacional seria ideal para a perpetuação de hábitos e costumes germânicos, os quais seriam repassados daquelas gerações para as próximas.

Com semelhante abordagem, Schneider (2002) fala sobre o caráter tendencioso da Maripá, que desenvolveu um programa de colonização em que se criou "uma imagem ao procedimento colonizador a partir da construção e difusão de uma série de significados atribuídos à figura dos colonos migrantes" (SCHNEIDER, 2002, p. 52).

Dessa forma, houve a seleção do elemento humano, a partir de suas características étnicas e hábitos, que deveriam corresponder ao discurso e aos objetivos da empresa colonizadora. "Estes procedimentos revelam práticas que dão a noção de um gerenciamento científico e racional, através do qual a noção de alteridade não escapava do olhar dos dirigentes" (SCHNEIDER, 2002, p. 57).

Atualmente, mesmo após seis décadas de colonização e cinco décadas de emancipação político-administrativa, o município continua mantendo o estilo europeu em construções em estilo germânico e na realização de eventos festivos ao longo do ano, principalmente por meio de incentivos públicos municipais que enfatizam sempre a germanidade da cidade.

Sobre o assunto, menciona Targanski:

Mesmo na atual configuração turística, cultural e arquitetônica da cidade, é possível perceber a influência da cultura germânica na região e, por outro lado, a ausência de características de outros tipos de imigrantes, embora também existam outras descendências (TARGANSKI, 2007, p. 28).

É o mesmo discurso de germanidade que se constatou na produção dos banners que serão analisados na próxima seção que, além de propagar essa imagem teuta, ao mesmo tempo, silencia as demais etnias presentes no município.

\section{A reprodução do discurso da germanidade nos banners}


Com base nos pressupostos da $A D$, verifica-se como o texto escrito e as imagens se organizam, considerando a relação da língua com a história, pois é trabalho do analista do discurso compreender como o texto funciona enquanto objeto linguístico-histórico. Portanto, na sequência, será analisada a materialidade linguística selecionada para o presente estudo.

Os três banners que formam o corpus deste estudo são coloridos e possuem várias fotos no seu interior de diferentes lugares do município rondonense. O primeiro a ser mencionado é o seguinte:

Figura 1 - Banner exposto na prefeitura de Marechal Cândido Rondon (PR).

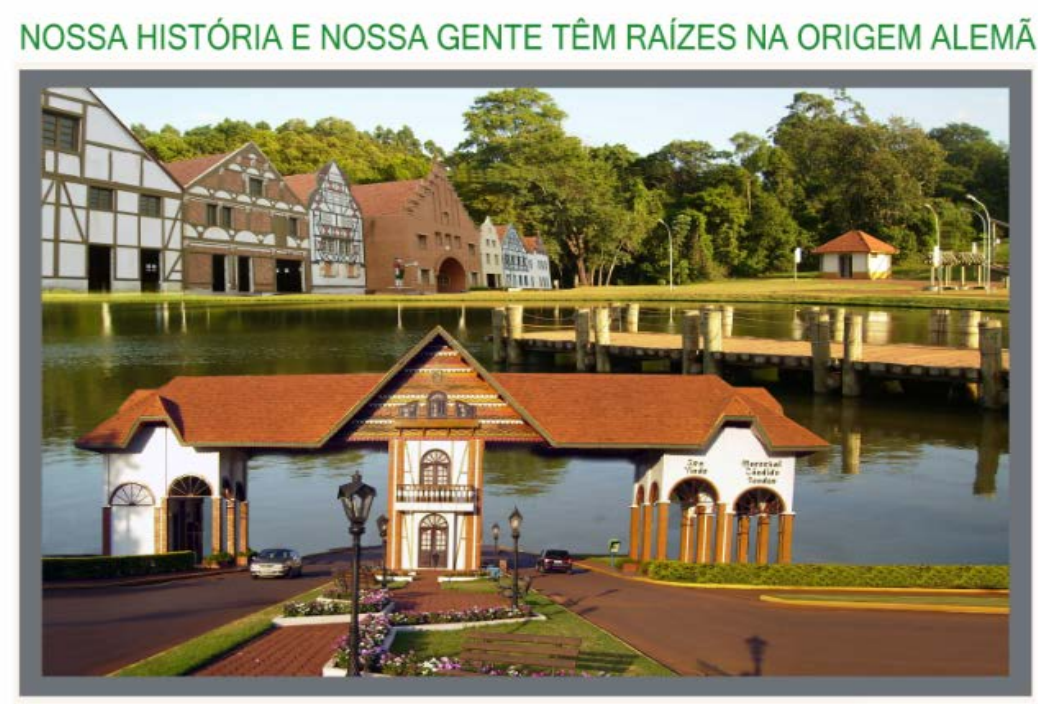

DIS MARECHAL

Fonte: Fotografado por Franciele Martiny, em outubro de 2012.

Na Figura 1, há uma montagem com fotografias de três obras públicas municipais, as quais também são comumente utilizadas em cartões postais e sites do município. São elas: o Centro de Eventos, na parte superior esquerda (obra inserida no Parque de Exposições, em que acontecem vários eventos oficiais e não oficiais do município e região); o lago municipal, na parte superior, à direita (inserido no Parque Ecológico do município, em área de lazer, aberta e arborizada); e o Portal de entrada da cidade em estilo germânico, na 
parte inferior. Os três ambientes ficam localizados em espaços diferentes, mas no banner aparecem juntos.

Sobre o Centro de Eventos, chamado "Werner Wanderer", cabe mencionar que o nome escolhido remete a um dos pioneiros do município, de origem alemã, político e atual representante oficial da Alemanha no Brasil. A obra, construída no ano 2000 e inaugurada em 23 de outubro de 2003, possui mais de seis mil metros quadrados, com capacidade de receber um público de até dez mil pessoas, sendo composta por 34 fachadas em estilo germânico, representando 34 cidades alemãs. Esse local é utilizado em vários eventos municipais.

O Parque Ecológico, também construído em formato germânico, foi encontrado em todas as páginas da internet analisadas no estudo anterior (MARTINY, 2010) e que, mais uma vez, aparece com destaque no banner do Poder Público municipal. Sendo tal parque a "porta" do município, cuja função é receber as pessoas, mostrando o estilo característico germânico em sua fachada como elemento diferenciador, marcador.

Esse discurso, enquanto interdiscurso, da germanidade, é o sempre-aí da interpelação ideológica da cultura germânica que está presente em Marechal Cândido Rondon. Aspecto que os sujeitos podem até desconhecer, mas, como estão habituados a escutarem as mesmas histórias idealizadas sobre 0 município, pelo já-dito, são afetados diretamente pelo inconsciente e pela ideologia.

Nesse sentido, à luz da $A D$ francesa, considera-se o texto não como portador de um sentido pronto pretendido por seu autor, mas como manifestação material de um discurso. Assim, não se pode dizer que há um sujeito consciente responsável pela produção dos banners, mas é o sujeito porta-voz de discursos, pois as ações, em grande parte, são feitas de forma inconsciente. 
Como já citado, em conformidade com Pêcheux (1969), os indivíduos são interpelados em sujeitos-falantes pelas Formações Discursivas (FDs) que thes são correspondentes. Dessa maneira, não se pode pensar o sentido e o sujeito sem pensar na ideologia e, ao mesmo tempo, não se pode pensar na ideologia sem pensar na linguagem.

Como afirma Possenti (1990, p. 8):

O que a análise do discurso faz, incorporando descobertas da teoria das ideologias e do inconsciente, é mostrar que a idéia de um sujeito completamente consciente, senhor de sua vontade, que faz o que decide é uma idéia que não resiste. [...], isto é uma ilusão.

Muitas vezes, os sujeitos-enunciadores ficam divididos entre o que está em seu interior e os discursos que os atravessam diariamente. O papel do inconsciente, também retratado por Mussalim (2001), mostra esse componente como uma forma de linguagem, que emana uma cadeia de significações, "como se houvesse sempre, sob as palavras, outras palavras, como se o discurso fosse sempre atravessado pelo discurso do Outro, do inconsciente" (MUSSALIM, 2001, p. 361).

Semelhante imagem do Portal também aparece em destaque no site oficial da prefeitura. Apesar de ter havido a troca de administração pública municipal, constatou-se que os elementos na disposição da página online mudaram, mas o discurso é muito semelhante ao site anterior, principalmente na imagem de abertura, e nas informações escritas no link "Nossa Cidade", que, novamente, reproduzem toda a questão da germanidade local e, assim, a mesma interpelação ideológica já mencionada.

Ressalta-se que o design do referido Portal foi eleito em concurso, conforme disposições do Edital da prefeitura $n^{\circ}$ 001/94. O regulamento previa que no projeto deveria ser especificado em qual região da Alemanha o autor buscou inspiração para o estilo apresentado. A vencedora foi uma arquiteta rondonense que baseou seu projeto em "fotografias e gravuras de edificações 
existentes em cidades do Norte da Alemanha: Lübeck, Hamburg, Bremen e Lüneburg" (GREGORY; STEIN, 2011, p. 371). Dessa forma, era pré-requisito o Portal possuir o estilo germânico.

O enunciado escrito ao alto das imagens, nos banners, por sua vez, aparece grafado com letras (em caixa alta) e em destaque na cor verde que faz parte da bandeira do município rondonense, outro símbolo oficial, juntamente com as cores vermelha e branca.

Na sequência deste estudo, segue o segundo banner que também apresenta o mesmo enunciado supracitado, no entanto, possui outras fotos de outras obras, as quais apresentam, novamente, traços da germanidade em suas fachadas.

Figura 2 - Banner exposto na prefeitura de Marechal Cândido Rondon (PR).

\section{NOSSA HISTÓRIA E NOSSA GENTE TÊM RAÍZES NA ORIGEM ALEMÃ}
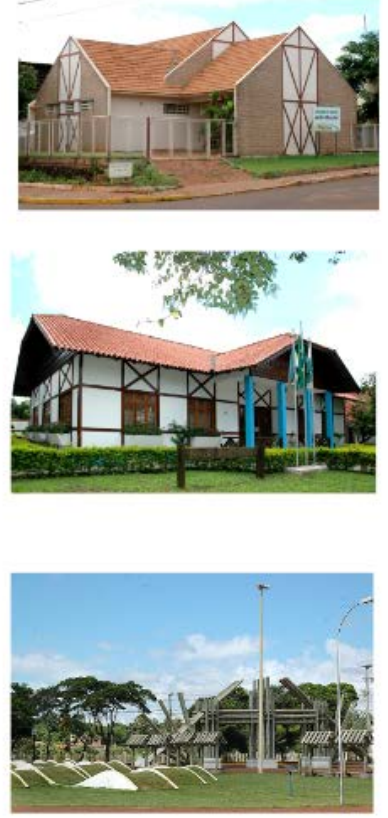

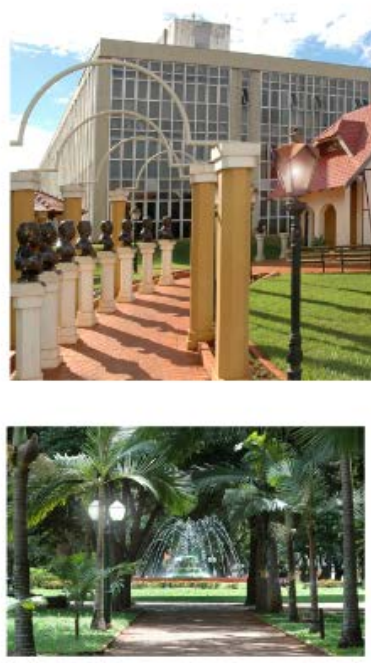

MARECHAL
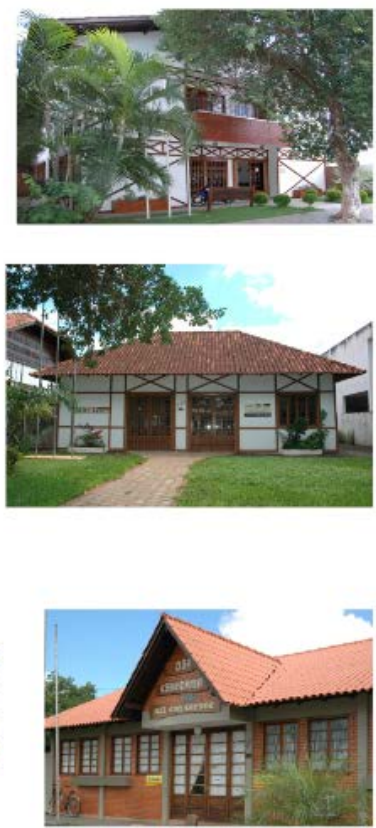

Fonte: Fotografado por Franciele Martiny, em outubro de 2012. 
Com exceção do chafariz e do Parque Ecológico, os demais prédios públicos que aparecem na Figura 2 possuem o estilo Enxaimel ${ }^{2}$ nas fachadas; são eles, na primeira coluna à esquerda, de cima para baixo: Posto de Saúde do Bairro São Lucas (todos os postos de saúde do município possuem semelhante fachada); instalações da Receita Federal e a entrada do lago municipal no Parque Adolfo Rieger; na coluna do meio, há a casa do memorial do município, situado ao lado da prefeitura, e duas fotos do chafariz da Praça central Willy Barth; na coluna da direita, apresenta-se a construção de dois andares que abriga o Poder Judiciário e a J ustiça do Trabalho; a instalação da Emater e as instalações do Ciretran/Detran.

O próprio ângulo das imagens reforça a presença do estilo arquitetônico que foi reproduzido ao longo dos anos e incentivado aos moradores. Assim, além de construir repartições públicas com estilo germânico, o Governo Municipal criou a lei $n^{\circ} 1627$ de 14/07/1986, que previa a isenção de imposto predial e territorial urbano (IPTU) em imóveis que seriam construídos no estilo denominado Enxaimel e Casa dos Alpes. Por isso também a presença de muitas residências e estabelecimentos comerciais em estilo germânico na cidade, principalmente no perímetro urbano.

Tal incentivo fiscal fazia parte de um projeto maior de germanização do município, visando, sobretudo, atrair turismo e riqueza para o município, por meio de uma

[...] comissão que elaborou projeto de lei encaminhado ao prefeito Ilmar Priesnitz que após estudar o documento, convocou os vereadores, o Rotary Club, a Maçonaria, o Lyons Club e outras entidades da cidade para discutir a ideia. A proposta principal era diferenciar a cidade, principalmente no aspecto arquitetônico. Ser diferente seria a fórmula para trazer turistas e riquezas para o município (GREGORY, STEIN, 2011, p. 361).

\footnotetext{
2 Trata-se de um estilo arquitetônico germânico, feito por uma técnica de construção manual, que era usada, primeiramente, no ambiente campesino e, após, durante os séculos XVII e XVIII, foi trazida ao meio urbano, com requintes artesanais, entre eles, madeiramento esculpido, floreiras e outros diversificados tipos de adereços, os quais eram misturados à estrutura original.
} 
Ser diferente, nesse caso, seria parecer um "pedaço" da Alemanha no Brasil, por conseguinte, não se assume então uma identidade brasileira, mas são ainda alemães residindo no Brasil, apesar de já serem descendentes, muitas vezes, de quarta, quinta e até sexta geração em terras brasileiras. Por exemplo, quando um falante se autonomeia ou chama alguém de 'alemão', no município de Marechal Cândido Rondon (o que é muito comum), não é, necessariamente, porque essa pessoa nasceu na Alemanha, mas, muito provavelmente, porque é descendente de imigrantes alemães ou de regiões próximas daquele país. Então, muitas vezes, questiona-se no momento em que chega alguém desconhecido na cidade: "você é alemão ou italiano?", pois a maioria dos habitantes é imigrante ou descendente de imigrantes alemães ou italianos, e essa seria uma maneira de identificação de grupos.

Também a Oktoberfest iniciou devido ao projeto de germanização supracitado, sendo que a festa simbolizava a alegria alemã, tendo incorporado, com adaptações e modificações, a gastronomia, a música e a língua dos alemães.

A Oktoberfest, reeditada a cada ano é plena de citações dos mitos fundantes da história. Apagando e silenciando os conflitos, as contradições, a história pontuada pelos diversos tempos vividos, acaba por apresentar e representar uma história mitificada, apologética, seletiva, cuja versão é trazida a público através de emblemas de um passado seletivo, pelos fazedores de festa (FLORES, 1997, p. 46).

O próprio slogan da festa, por muitos anos, foi "A mais germânica do Paraná". No entanto, recentemente, foi substituído por "A mais simpática do Brasil", uma vez que já não é mais considerada a maior festa germânica do Paraná, bem como não se caracteriza mais tanto pela cultura alemã, pois não há mais atividades culturais durante o evento, apenas baile e chope. Iniciativas mais recentes têm tentado resgatar a cultura alemã no citado evento. 
Por fim, apresenta-se o terceiro banner.

Figura 3 - Banner exposto na prefeitura de Marechal Cândido Rondon (PR). NOSSA HISTÓRIA E NOSSA GENTE TÊM RAIZZES NA ORIGEM ALEMÃ
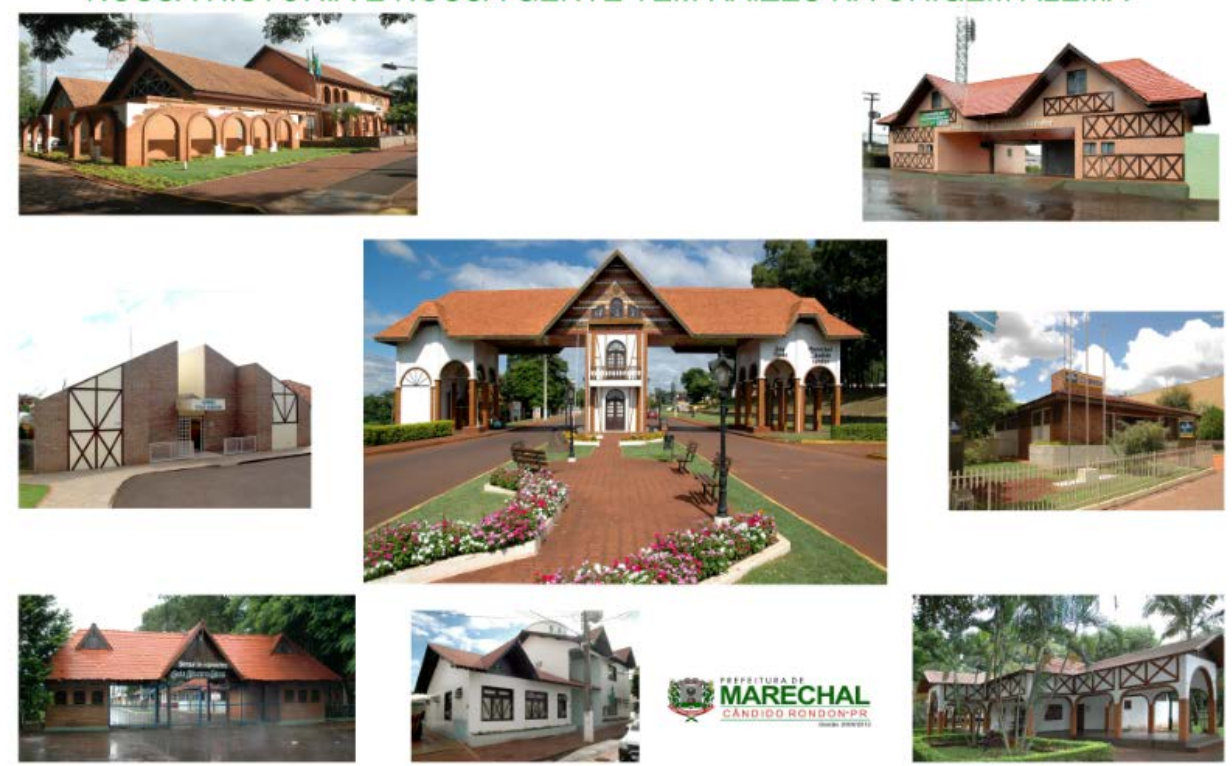

20.7 MARECHAL

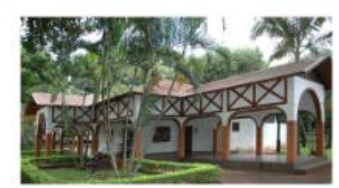

Fonte: Fotografado por Franciele Martiny, em outubro de 2012.

Conforme a Figura 3, verifica-se que este banner possui como elemento central o já mencionado portal de entrada da cidade. Na primeira coluna, de cima para baixo, há a imagem do Fórum, o Posto de Saúde do bairro localizado no J ardim Primavera e o portão de entrada do Parque de Exposições. Na coluna do meio, há, então, o portal e abaixo dele a fachada do SAAE (Senviço Autônomo de Água e Esgoto) juntamente com a logomarca da prefeitura. $\mathrm{Na}$ coluna da direita, também de cima para baixo, há o portal de entrada do Estádio Municipal, as instalações dos Correios e a Casa do Artesão (situada na praça central da cidade). Mais uma vez, a maior parte das construções apresentadas tem o estilo germânico, o que é destacado nas fotos.

Esse modelo arquitetônico, que foi incentivado para dar característica à cidade germânica, muitas vezes, gera críticas sobre sua produção, uma vez que se tornou um atrativo turístico para os visitantes devido aos elementos decorativos em suas fachadas, que procuram reproduzir estilos da arquitetura alemã, predominante do século XIX. Embora essas imitações arquitetônicas 
tentem buscar o resgate e a preservação da tradição germânica, muitas apresentam uma mistura de estilos e materiais equivocados, trazendo à tona um modelo não elaborado das fachadas das cidades alemãs. Situação que fica mais evidenciada quando visitantes alemães chegam à cidade e comentam a dissonância com a arquitetura de lá.

O enunciado da Figura 3 é o mesmo dos outros dois banners e reforça os mesmos efeitos de sentido de que o município é alemão, de "raiz" - remetendo à colonização, a origem do município - e de "gente", remetendo aos descendentes de (i)migrantes. Portanto, observa-se a função ideológica do signo linguístico utilizado na construção do enunciado na relação estabelecida com o caráter histórico que carrega a palavra, no discurso oficializado, refratando valorações sociais presentes no município em questão.

Orlandi (2005) menciona que as palavras de um determinado discurso remetem a outras cujos sentidos são anteriores pela memória discursiva e pela formação ideológica. Esta fica expressa no logotipo reproduzido pela prefeitura que é marca registrada nos três banners, localizado na parte debaixo do material.

Com pequenas exceções, já mencionadas, todas as imagens presentes nos três banners mostram o município sempre representado pelos traços germânicos nas suas construções, sendo todas instalações de poderes públicos municipais, estaduais e federais.

Como afirma Orlandi (2005, p. 20), o sujeito é afetado "pelo real da língua e pelo real da história, não tendo controle sobre o modo como elas o afetam. Isso redunda em dizer que o sujeito discursivo funciona pelo inconsciente e pela ideologia".

Ao colocar apenas imagens germânicas se reafirma a "supremacia" dos colonizadores que continuam mantendo a localidade essencialmente alemã, não valorizando as demais culturas existentes, que permanecem silenciadas nos discursos. 
O enunciado dos banners marca bem a situação quando afirma "nossa gente" e "nossa história" possuem as "raízes" alemães, ou seja, as bases colonizatórias são germânicas. Embora possam existir mais recentemente outras etnias na região, propaga-se que a origem continua sendo a mesma e isso não pode ser mudado - é a historicidade sempre retomada, todavia de forma "embelezada", "engrandecida", pois não são mencionadas as intimidações aos demais povos.

Além disso, enfatiza-se, nesse enunciado, o uso do pronome pessoal, que marca proximidade do poder público e de seus governantes com a população, valorizando essa característica como a mais importante da "gente", da sua cultura e da sua história. Não se faz diferenciação entre quem tem descendência alemã e quem não tem.

Destarte, as "raízes" são motivos de orgulho para os governantes que continuam reproduzindo os mesmos enunciados da empresa Colonizadora na divisão das terras de modo direcionado, pois a localidade era para ser mesmo uma "terra de alemães", mesmo estando agora em outro país. Nesse sentido, há um trocadilho muito conhecido e falado frequentemente pelos visitantes e pelos próprios munícipes "Rondon, cidade dos alemão". A falta de concordância é proposital e remete à dificuldade que muitos dos descendentes alemães tiveram ao aprender a falar o português.

O Poder Público, dentro da formação discursiva de que participa, não diz que o município possui outras raízes ou que agora é uma região de vários povos. Dentro dessa formação ideológica, só poderia reproduzir o mesmo discurso de germanidade, existente desde sempre. Para Orlandi (2005, p. 46), "as palavras recebem seus sentidos de formações discursivas em suas relações. Este é o efeito da determinação do interdiscurso (da memória)".

Como afirma Orlandi (2007, p. 174), ao se escolher certas palavras se deixa de utilizar outras, esta também é uma forma de silenciar alguns aspectos 
enaltecendo outros, que, ideologicamente, são considerados mais importantes do que os outros.

A posição dos sujeitos dentro da referida formação discursiva, como afirma Orlandi (2005, p. 43), traz limitações sobre o que dizer. Portanto, a ideologia está presente na escolha que tais pessoas fizeram ao reproduzir os banners, pois o conceito de germanidade do município está cristalizado na população, isto é, está na memória discursiva, dando a impressão de que o sujeito é livre para pensar e dizer o que quer, ou seja, que não é assujeitado.

Em outras palavras, o sujeito não é livre para dizer o que quer, mas é levado, sem que tenha consciência disso (e aqui reconhecemos a propriedade do conceito lacaniano de sujeito para a AD), a ocupar seu lugar em determinada formação social e enunciar o que lhe é possível a partir do lugar que ocupa (MUSSALIM, 2001, p. 110).

Tais apontamentos retomam novamente o conceito da $A D$ de formação ideológica, uma vez que há a reprodução da mesma história, do já-dito, fomentando os mesmos efeitos de sentidos que estão estabelecidos nos sujeitos de que efetivamente "Rondon é a cidade dos alemães", tanto pelas raízes de seu povo, quanto pelos eventos e pelos enunciados proferidos em sites, meios de comunicação e no discurso oficial.

Nota-se no município a presença de grupos que ainda se identificam como descendentes de alemães, e que procuram símbolos que representam a germanidade, a fim de manter e construir identidades vinculadas a este passado imaginário.

\section{Considerações finais}

De acordo com a análise realizada ao longo deste estudo, verifica-se, novamente, o caráter de historicidade da enunciação baseada no discurso da germanidade no município rondonense por meio, dessa vez, na arquitetura. 
Há, portanto, uma memória discursiva que é retomada pelos governantes municipais, que interpelados pela ideologia reproduzem e perpetuam uma identidade construída na cidade de "raízes" alemãs.

O suporte teórico da AD possibilitou relacionar como o texto escrito e as imagens se organizam nos banners, considerando a relação da língua com a história, pois é trabalho do analista do discurso compreender como o texto funciona enquanto objeto linguístico-histórico, para além da situação puramente linguística.

Nesse sentido, na $A D$, a compreensão conceitual da subjetivação e dos processos de identificação recebe um contorno específico quando são considerados o inconsciente e a ideologia como constituintes do sujeito, encontrando-se materialmente inscritos na língua. Cabe ao analista examinar, na prática da linguagem, quais são mais prováveis, quais se realizam e quais restam como possíveis, uma vez que o discurso é caracterizado pela incompletude dos sentidos e dos sujeitos.

Portanto, por meio da mesma enunciação presente nos banners e na reprodução das imagens de construções em estilo germânico, perpetuam-se discursos anteriores de germanismo do município rondonense, pela memória discursiva, criando e recriando os mesmos efeitos de sentido e perpetuando uma identidade construída pelos colonizadores, que é sempre retomada pelo Poder Público em suas ações e incentivos.

Assim, a associação do povo rondonense com a cultura germânica é construída como profundamente entranhada, vinda de um passado que esmoreceu ao longo do tempo e está vivo ainda hoje.

\section{Referências}

FLORES, Maria Bernadete Ramos. Oktoberfest. turismo, festa e cultura na estação do chopp. Florianópolis: Letras Contemporâneas, 1997. 
GREGORY, Valdir; STEI N, Marcos Nestor. Migrações e germanidade: oeste do Paraná e Marechal Cândido Rondon. In: VITECK, Harto. Imigração alemã no Paraná. 180 anos: 1829-2009. Marechal Cândido Rondon: Germânica, 2011.

GÜTTGES, Arlen Alberto; VALQUES, Igor J osé Botelho. A arquitetura germânica e suas influências nas edificações brasileiras: o caso de M. C. Rondon. Akrópolis, Umuarama, v. 11, n. 3, jul./set., 2003. Disponível em: $<$ http://www.google. com.br/url?sa=t\&rct=j\&q=\&esrc=s\&source=web\&cd=8\&v ed=0CEwQFjAH\&url=http\%3A\% 2F\%2Frevistas.unipar. br\%2Fakropolis\%2Farticl e\%2Fdownload\%2F377\%2F343\&ei=2PQVU8jFJ 4ndkQfZylCYDg\&usg=AFQjCNF ykfrOrUv6DskmNbdo9Z71ChnbGg\&bvm=bv.62286460,d.eW0>. Acesso em: 15 jan. 2014.

MARTINY, Franciele Maria. Rondon a cidade dos alemães: a imagem da germanidade de Marechal Cândido Rondon reproduzida na internet.

SEMI NÁRIO INTERNACIONAL, ETNI A, DIVERSIDADE E FORMAÇÃO, 1., 2010, Cascavel. Anais... Cascavel: Unioeste, 2010. p. 1-8.

MUSSALIM, Fernanda. Análise do Discurso. In: ; BENTES, Anna Christina. Introdução à lingüística. 9. ed. São Paulo: Cortez, 2001, p. 101-139.

ORLANDI, Eni Puccinelli. Análise do discurso. princípio e procedimentos. 4. ed. Campinas: Pontes, 2005.

ORLANDI , Eni Puccinelli. As formas do silêncio. No movimento dos sentidos. 6. ed. Campinas: Unicamp, 2007.

PÊCHEUX, Michel. L'analyse automatique du discours. Paris: Dunod, 1969.

POSSENTI, Sírio. Apresentação da análise do discurso. Revista de estudos linguísticos, São J osé do Rio Preto, p 1-12, 1990.

POSSENTI, Sírio. Teoria do discurso: um caso de múltiplas rupturas. In: MUSSALIN, Fernanda, BENTES, Anna Christina (Org. ). Introdução à linguística: domínios e fronteiras. São Paulo: Cortez, 2003.

SAATKAMP, Venilda. Desafios, lutas e conquistas: história de Marechal Cândido Rondon. Cascavel: Assoeste, 1984.

SCHNEIDER, Claércio Ivan. Os senhores da terra: produção de consensos na fronteira (Oeste do Paraná, 1946-1960). Curitiba: Aos Quatro Ventos, 2002.

TARGANSKI, Sérgio. Rumo ao novo Eldorado. Marechal Cândido Rondon: Editora Germânica, 2007. 